\title{
Aldosterone and Renin Concentration Abnormally Elevated in a Cohort of Normotensive Pregnant Women
}

\section{Valentina Pasten}

Pontificia Universidad Catolica de Chile

ALEJANDRA TAPIA-CASTILLO ( $\nabla$ aletapia.castillo@gmail.com )

Pontificia Universidad Catolica de Chile https://orcid.org/0000-0002-6081-1468

Carlos E. Fardella

Pontificia Universidad Catolica de Chile

Andrea Leiva

Universidad San Sebastian

Cristian A. Carvajal

Pontificia Universidad Catolica de Chile

\section{Research Article}

Keywords: normotension, pregnancy, renin-angiotensin-aldosterone system, extracellular vesicles

Posted Date: June 14th, 2021

DOl: https://doi.org/10.21203/rs.3.rs-595582/v1

License: (9) This work is licensed under a Creative Commons Attribution 4.0 International License. Read Full License 


\section{Abstract}

During pregnancy the renin-angiotensin-aldosterone system (RAAS) undergo major changes to preserve normal blood pressure (BP), placenta blood flow and ensure a good pregnancy outcome. Abnormal aldosterone-renin metabolism is a risk factor for arterial hypertension and cardiovascular risk, but its association to pathological conditions in pregnancy remains unknown. Hence, clinical and subclinical novel biomarkers associated to these pathological conditions are encouraged to be identified. Aim: To study a cohort of normotensive pregnant women according to their serum aldosterone and plasma renin levels and assay their small extracellular vesicles (sEV) and a specific protein-cargo (LCN2, AT1R). Methods: A cohort of 54 normotensive pregnant women at term gestation. We determined the BP, serum aldosterone and plasma renin concentration. In a subgroup, we isolated their plasma sEVs and semiquantify two EV-proteins (AT1R, LCN2). Results: We set a normal range of aldosterone and renin based in the interquartile range. We identified $5 / 54(9 \%)$ pregnant women with elevated aldosterone and low renin levels, and 5/54(9\%) other pregnant women with low aldosterone and elevated renin levels. No differences were found in sEV-LCN2 nor sEV-AT1R. Conclusion: We found 18\% normotensive pregnant women having either high aldosterone or high renin levels, suggesting a subclinical status similar to a primary aldosteronism or a hyperreninemia. Both would evolve to pathological conditions in presence a second challenge affecting the maternal vascular physiology or the BP. sEVs and its specific cargo are encouraged to be further studied in order to clarify its role as potential biomarkers of RAAS alterations in pregnant women.

\section{Introduction}

During pregnancy, the renin-angiotensin-aldosterone system (RAAS) undergo major changes. Aldosterone and renin are upregulated during pregnancy to ensure an increase in maternal volemia and good placental perfusion $[1,2]$. Circulating prorenin and renin increase 4 -fold by 10 weeks gestation and plateaus at 22 weeks gestation by elevated estrogen and extrarenal release by the ovaries and maternal decidua [3] [4]. Aldosterone and its regulator Angiotensin II (Ang-II) also increase during pregnancy [5]. The actions of Ang II including aldosterone synthesis are mediated through the Ang-II type-1 receptor (AT1R) [6-8]. AT1R is expressed in placenta and increased in pathologies such as preeclampsia [9, 10]. However, to date the regulation of AT1R abundance in plasma of pregnant women is unknown.

Circulating aldosterone binds to mineralocorticoid receptors (MR) [11-13] and plays a crucial role regulating body fluid volume and blood pressure. Aldosterone increases around 10 -fold at term pregnancy [4], however, pathophysiological effects of increased aldosterone over MR are mitigated in pregnancy due to progesterone, which act as antagonist of $\operatorname{MR}[14,15]$ and also by inhibition of the CYP11B2 activity in adrenal tissue $[16,17]$. MR activation by aldosterone increases circulating and urinary lipocalin-2 protein ( $L C N 2$, also called NGAL), which has been proposed as a surrogate biomarker of MR activation by aldosterone [13, 18] [19]. 
Currently, experimental and clinical studies have demonstrated that changes in concentration and/or cargo of sEVs or exosomes are potential biomarkers of disease in non-pregnant and pregnant population [20-24]. The presence of LCN2 in small extracellular vesicles (sEVs) has been also suggested as an early marker of renal injury and MR activation $[13,19,25]$, but there is no information supporting changes in this novel biomarker associated to high blood pressure, aldosterone or renin levels in pregnancy. Similar to LCN2 [19], the presence of AT1R $[26,27]$ in circulating sEV associated to changes in RAAS in pregnant women remains unknow.

With this information, the aim of this study was to identify the normal levels of aldosterone, and plasma renin in normotensive pregnant women, and further to identify women with abnormal levels of this hormones [28]. In addition, we explore the presence of plasma sEVs and its protein cargo LCN2 and AT1R in these pregnant women.

\section{Material And Methods}

\section{Subjects}

This study was performed in 54 Chilean normotensive women in the third trimester of pregnancy $(\geq 37$ weeks of gestation) from the Hospital Clínico UC-CHRISTUS, Chile. Normotension was determined according to the 2017 ACC/AHA Guidelines for High Blood Pressure [28]. All the women included in this study had single pregnancies; no intrauterine infections or obstetric complications, no chronic pathologies such as kidney failure, heart failure, chronic liver damage or endocrinopathies and absence of exogenous treatment with mineralocorticoids or glucocorticoids. Subjects with pre-gestational and gestational diabetes, intrauterine growth restriction, fetal malformations, chronic hypertension, hypertensive disorder of pregnancy or other maternal pathologies were excluded from this study. Women previously diagnosed with secondary causes of hypertension, such as primary aldosteronism, familial hyperaldosteronism (FH) (OMIM 103900), apparent mineralocorticoid excess (AME) (OMIM 218030), hypercortisolism, and renovascular disease, were also excluded from this study. General maternal (i.e., age, height, weight and blood pressure) and neonatal (i.e., sex, gestational age, weight and height) variables were obtained from the clinical records. All subjects included in this study signed a written informed consent in accordance with the Helsinki Declaration and was approved by the ethical Committee of the Faculty of Medicine (CEC-18081004), Pontificia Universidad Católica de Chile.

\section{Classification of pregnant women based in aldosterone and renin levels}

Pregnant women were classified by aldosterone and renin levels in controls and women with high aldosterone or renin levels $[29,30]$. Controls pregnant women were 44 subjects with normal aldosterone and renin levels (Fig. 1). Women with serum aldosterone greater than percentile 75 th $(115.3 \mathrm{ng} / \mathrm{dL})$ with a concomitant low renin concentration (lower than percentile 25th : $34.9 \mathrm{uUI} / \mathrm{ml}$ ) were categorized as elevated-aldosterone and low-renin (EALR) (Fig. 1A). Otherwise, women with a low aldosterone (lower 
than percentile 25th : $37 \mathrm{ng} / \mathrm{dL}$ ) and a concomitant renin concentration greater than percentile 75 th (62.5 $\mathrm{uUl} / \mathrm{mL}$ ) were categorized as low-aldosterone and elevated-renin (EALR) (Fig. 1B).

\section{Biochemical assay}

Serum aldosterone (LIAISON® Aldosterone (310450)) and direct plasma renin concentration (DRC) (LIAISON® Direct Renin (code 310470)) were measured by chemiluminescent immunoassay (CLIA) technology on an automated chemiluminescent analyzer (Liaison XL/DiaSorin, Saluggia, Vercelli, Italy), with reported coefficients of variation of $9.5 \%$ for $6.7 \mathrm{ng} / \mathrm{dl}$ and $5.6 \%$ for $28.8 \mathrm{ng} / \mathrm{dl}$ for plasma aldosterone, and $13 \%$ for $5.8 \mathrm{mlU} / \mathrm{ml}$ and $7.3 \%$ for $107.5 \mathrm{mlU} / \mathrm{ml}$ for the DRC in the clinical laboratory of the Hospital Clínico UC-CHRISTUS.

Serum cortisol and cortisone were quantified using mass spectrometry (LC-MS/MS), validated according to the parameters suggested by the Food and Drug Administration and Clinical and Laboratory Standards Institute, using deuterated internal standards of cortisol and cortisone (cortisol-d4 and cortisone-d2), in an Agilent 1200 series HPLC equipment coupled to an ABSciex 4500 QTrap mass spectrometer [31].

\section{Isolation of small EVs from maternal plasma samples}

Small EVs (exosomes) were isolated by ultracentrifugation (UCF) from a plasma sample (500 $\mu \mathrm{L})$ of 18 pregnant women (including 4 EALR, 4 LAER and 10 control women) as described [32]. Briefly, samples were diluted in phosphate buffer saline (PBS) supplemented with calcium and magnesium (DPBS) and centrifuged $\left(4^{\circ} \mathrm{C}, 2.000 \mathrm{~g}, 30 \mathrm{~min}\right)$ to eliminate cell debris. The supernatant was centrifuged $\left(4^{\circ} \mathrm{C}, 12.000 \mathrm{~g}\right.$, $45 \mathrm{~min})$ and transferred to UCF tubes, filtered with $0.22 \mu \mathrm{m}$ filter and then centrifuged $\left(4^{\circ} \mathrm{C}, 200.000 \mathrm{~g}, 1.5\right.$ h) (UCF Thermo-Sorvall WX80+). The obtained supernatant was discarded, and the pellet resuspended in $4 \mathrm{~mL}$ of DPBS and centrifuged again $\left(4^{\circ} \mathrm{C}, 200.000 \mathrm{~g}, 1.5 \mathrm{~h}\right)$. Finally, sEVs pellets were resuspended in 100 $\mu \mathrm{L}$ of PBS or RIPA and stored at $-20^{\circ} \mathrm{C}$.

\section{Quantification of sEVs by Nanoparticle Tracking Analysis (NTA)}

sEVs samples were diluted with PBS to obtain a concentration range between 20 and 100 particles per frame (optimal greater than 20 particles per frame). The samples were analyzed using the NS300 instrument (Malvern, UK) with the NanoSight NTA 3.0 Nanoparticle Tracking and Analysis software (Version Build 0064). The videos (two videos per sample) were processed and analyzed as previously described, which inform the mean, mode, and median particle size together with an estimated number of particles per $\mathrm{mL}$ of plasma [33].

\section{Determination of sEV morphology by Transmission Electron Microscopy}

sEVs shape and size was determined by transmission electron microscopy as described [33]. For this, 15 $\mu \mathrm{L}$ sEVs pellet was added onto a carbon-coated copper grid (300 mesh) for $1 \mathrm{~min}$ and stained with $2 \%$ 
uranyl acetate for $1 \mathrm{~min}$. Grids were visualized at $80 \mathrm{kV}$ in a Tecnai transmission electron microscopy (Phillips, Finland).

\section{Identification of characteristic EV proteins, LCN2 and AT1R by western blot}

sEVs were resuspended in RIPA buffer (ThermoFisher Scientific, USA) and the protein content was determined with the bicinchoninic acid (micro-BCA) Protein Assay kit (ThermoFisher Scientific, USA). Proteins $(30 \mu \mathrm{g})$ from the EV lysate were separated by polyacrylamide gel electrophoresis in denaturing and reducing conditions, transferred to polyvinylidene difluoride membranes and later probed with primary rabbit polyclonal anti-TSG101 $\left(1: 10.000,18 \mathrm{~h}, 4^{\circ} \mathrm{C}\right)\left(\right.$ Abcam, UK) and anti-AT1R $\left(1: 200,18 \mathrm{~h}, 4^{\circ} \mathrm{C}\right)$ (Sigma-Aldrich, USA), and goat polyclonal anti-LCN2 (1:200, $\left.18 \mathrm{~h}, 4^{\circ} \mathrm{C}\right)$ (R\&D systems, USA) antibodies. After wash the membranes were incubated ( $1 \mathrm{~h}$, room temperature) with secondary horseradish peroxidase-conjugated goat anti-rabbit (ThermoFisher Scientific, USA) or rabbit anti-goat antibody (Abcam, UK) as described [34]. Proteins were detected by enhanced chemiluminescence and a semiquantitative analysis was performed densitometry using the software ImageJ (NIH, USA).

\section{Statistical Analysis}

Values are presented as the median [interquartile range] or mean \pm standard deviation (range). Comparisons between two groups were performed by Student's t-test for parametric data or MannWhitney u-test for non-parametric data. A value of $p<0.05$ was considered statistically significant. Data analysis and plotting were performed with software GraphPad Prism 7.0 (GraphPad Software Inc., USA).

\section{Results}

\section{Identification of groups of normotensive pregnant women with either high plasma aldosterone or high renin levels}

All women participating in this study had normal blood pressure (SBP $<120 \mathrm{mmHg}$ and DBP $<80 \mathrm{mmHg}$ ), with a mean of BP of average $102.5 \mathrm{mmHg}$ (Table 1). We identified 44 pregnant women with normal aldosterone or normal renin levels, which were considered as controls (Table 1) (Fig. 1). In our cohort, 9\% (5/54) were identified as having elevated aldosterone and low renin (EALR) (Table 1) (Fig. 1A). In EALR group, the aldosterone levels were two-fold higher in pregnant women compared to controls $(130 \mathrm{ng} / \mathrm{dL}$ vs $65.6 \mathrm{ng} / \mathrm{dL}, \mathrm{p}<0.0001$ ), and renin levels were 64\% significantly lower compared to controls (34.1 $\mathrm{uUI} / \mathrm{mL}$ vs $44.7 \mathrm{uUl} / \mathrm{mL}, \mathrm{p}<0.05)$. The ARR was three-fold higher in pregnant women with EALR compared to controls (4.9 vs $1.5, \mathrm{p}<0.0001)$ (Table 1$)$. 
Table 1

Clinical and biochemical characteristics of pregnant women and their newborns.

$\begin{array}{lllll}\text { Variables } & \text { Total }(n=54) & \begin{array}{l}\text { Control }(n= \\ 44)\end{array} & \operatorname{EALR}(n=5)\end{array} \quad \operatorname{LAER}(n=5)$

Maternal variables

\begin{tabular}{|c|c|c|c|c|}
\hline Age [years] & $31[25.8-34.3]$ & $30[26-32.8]$ & $31[28-34.5]$ & $\begin{array}{l}36[22.5- \\
36.5]\end{array}$ \\
\hline Height [47] & $161[158-165]$ & $\begin{array}{l}161[158- \\
165]\end{array}$ & 165 [163-168] & $\begin{array}{l}158[154- \\
161]\end{array}$ \\
\hline Weight 3th trimester [kg] & 79 [70.5-86.5] & 79 [71-87] & 79 [70.5-91] & 79 [60.5-92] \\
\hline Weight gain [kg] & $12[8.5-14]$ & $12[9.5-14]$ & $12[9.5-19.5]$ & $10[6-13]$ \\
\hline $\begin{array}{l}\text { BMI at 3th trimester } \\
{\left[\mathrm{kg} / \mathrm{m}^{2}\right]}\end{array}$ & $\begin{array}{l}30.5[27.1- \\
33.4]\end{array}$ & $\begin{array}{l}30.5[27.3- \\
33.2]\end{array}$ & $29[26.5-32.4]$ & $\begin{array}{l}31.2[24.7- \\
36.7]\end{array}$ \\
\hline $\begin{array}{l}\text { SBP at 3th trimester } \\
\text { [mmHg] }\end{array}$ & $\begin{array}{l}107.5[102.8- \\
112.3]\end{array}$ & $\begin{array}{l}108[102- \\
112]\end{array}$ & $\begin{array}{l}107[102.5- \\
110.5]\end{array}$ & $\begin{array}{l}120[103.5- \\
128]\end{array}$ \\
\hline $\begin{array}{l}\text { DBP at 3th trimester } \\
\text { [mmHg] }\end{array}$ & $67[62-70]$ & $66.5[62-70]$ & $68[65.5-69]$ & $66[63.5-74]$ \\
\hline
\end{tabular}

Mineralocorticoids

\begin{tabular}{|c|c|c|c|c|}
\hline Aldosterone [ng/dL] & $\begin{array}{l}65.2[36.8- \\
116.6]\end{array}$ & $\begin{array}{l}65.8[40.6- \\
96]\end{array}$ & $\begin{array}{l}130[122.5- \\
205] \star \star \star \star\end{array}$ & $\begin{array}{l}30.8[18.2- \\
36.8]^{\star}\end{array}$ \\
\hline Renin $[u U l / m L]$ & $44.3[35-60.9]$ & $\begin{array}{l}44.7[34.9- \\
58.3]\end{array}$ & $34.1[6-35]$ * & $\begin{array}{l}74.2[62.8- \\
94.9]^{*}\end{array}$ \\
\hline ARR & $1.5[0.7-2.7]$ & $1.5[0.8-2.3]$ & $\begin{array}{l}4.9[3.6- \\
29.8] \star \star \star \star\end{array}$ & $\begin{array}{l}0.36[0.3- \\
0.4]^{\star \star}\end{array}$ \\
\hline
\end{tabular}

Glucocorticoids

$\begin{array}{lllll}\text { Cortisol }[\mathrm{ug} / \mathrm{dL}] & 28.9[21.6- & 27.9[21.5- & 35[27.9-52.7] & 31.5[19- \\ & 41.6] & 41.1] & & 41.3]^{[-}\end{array}$

$\begin{array}{lllll}\text { Cortisone }[\mathrm{ug} / \mathrm{dL}] & 6.4[5.6-7.3] & 6.2[5.6-7.1] & 7.3[6.2-7.9] & 6.3[4.9-7.3] \\ \text { CCR } & 4.6[3.7-5.7] & 4.3[3.36-5.6] & 5[4.3-7] & 4.9[3.9-5.7]\end{array}$

Newborn variables

$\begin{array}{lllll}\text { Sex [female/male] } & 32 / 22 & 7 / 6 & 4 / 1 & 4 / 1\end{array}$

Women with elevated aldosterone and low renin (EALR); Women with low aldosterone and elevated renin (LAER). Weight, body mass index (BMI), SBP and DBP were determined at 3rd trimester. ARR, aldosterone to renin ratio; CCR, cortisol to cortisone ratio. Comparisons between two groups were performed by Student's t-test for parametric data or Mann-Whitney u-test for non-parametric data. *P $<0.05, \star \star P<0.001, \star \star \star * P<0.0001$ versus corresponding values in control group. Clinical data are presented as median and interquartile range; biochemical data are presented as mean \pm S.D (range). 


\begin{tabular}{|c|c|c|c|c|}
\hline Variables & Total $(n=54)$ & $\begin{array}{l}\text { Control }(n= \\
44)\end{array}$ & $\operatorname{EALR}(n=5)$ & $\operatorname{LAER}(n=5)$ \\
\hline Gestational age [weeks] & $39.3[38.6-40]$ & $\begin{array}{l}39.3[38.7- \\
40]\end{array}$ & 38.9 [38.3-39.4] & $\begin{array}{l}38.1[37.7- \\
39.7]\end{array}$ \\
\hline Birth weight [grams] & $\begin{array}{l}3315[3090- \\
3635]\end{array}$ & $\begin{array}{l}3300[3090- \\
3635]\end{array}$ & $\begin{array}{l}3630[3395- \\
3905]\end{array}$ & $\begin{array}{l}3180[3040- \\
3440]\end{array}$ \\
\hline Height [cm] & 50 [49-51] & $50[49-51]$ & $51[50.5-52.5]$ & $\begin{array}{l}48.8[48.1- \\
49.8]\end{array}$ \\
\hline $\begin{array}{l}\text { Ponderal index [grams } \\
\left./ \mathrm{cm}^{3} \mathrm{x} 100\right]\end{array}$ & $2.6[2.6-2.8]$ & $2.6[2.5-2.8]$ & $2.7[2.6-2.8]$ & $2.7[2.6-2.9]$ \\
\hline \multicolumn{5}{|c|}{$\begin{array}{l}\text { Women with elevated aldosterone and low renin (EALR); Women with low aldosterone and elevated } \\
\text { renin (LAER). Weight, body mass index (BMI), SBP and DBP were determined at 3rd trimester. ARR, } \\
\text { aldosterone to renin ratio; CCR, cortisol to cortisone ratio. Comparisons between two groups were } \\
\text { performed by Student's t-test for parametric data or Mann-Whitney u-test for non-parametric data. *P } \\
<0.05,{ }^{* * P}<0.001, * \star \star P<0.0001 \text { versus corresponding values in control group. Clinical data are } \\
\text { presented as median and interquartile range; biochemical data are presented as mean } \pm \text { S.D (range). }\end{array}$} \\
\hline
\end{tabular}

Similarly, a 9\% (5/54) of pregnant women were identified as having low aldosterone and elevated renin (LAER) (Table 1) (Fig. 1B). These five women were different than those identified in EALR group. The data corresponding to control women are shown in Table 1 and Fig. 1B. In pregnant women with LAER, aldosterone levels were $70 \%$ lower $(30.8 \mathrm{ng} / \mathrm{dL}$ vs $65.8 \mathrm{ng} / \mathrm{dL}, \mathrm{p}<0.05)$, renin levels were higher $(74.2$ $\mathrm{uUI} / \mathrm{mL}$ vs $44.7 \mathrm{uUI} / \mathrm{mL} p<0.05)$ and ARR was four-fold lower $(0.36$ vs $1.5, p<0.001)$ compared to control pregnant women (Table 1).

Serum cortisol, cortisone and cortisol to cortisone ratio (CCR) were similar in different groups (Table 1). Regarding the neonatal variables, we did not observe any difference in EALR and LAER group compared to control neonates (Table 1).

\section{Identification and characterization of plasma extracellular vesicles in EALR and LAER groups}

Plasma sEVs were isolated from 18 pregnant women of our cohort, representative 10 control, 4 EALR and 4 LAER. The particle size ranged between $50-150 \mathrm{~nm}$ for all samples (Fig. 2A). The morphology of the isolated $s E V s$ was determined by transmission electron microscope. $s E V s$ showed the characteristic morphology of round donut shape between 30-150 nm (Fig. 2B). The presence of the sEVs marker TSG101 was confirmed by western blot in the isolated sEVs (Fig. 2C). No significant differences were observed in SEVs concentration and mode in different study groups (Table 2) with exemption of the higher mode of particles $(102.4 \pm 0.8$ vs $79.8 \pm 19.8, p<0.05)$ in LAER group compared to controls. 
Table 2

Concentration and mode by NTA of $\mathrm{sEV}$ s isolated from normotensive pregnant women.

Particle concentration (particles/mL plasma)

Controls

$7.9 \times 10^{8} \pm 3 \times 10^{8}\left(4.7 \times 10^{8}-1 \times 10^{9}\right)$

EALR

$7.3 \times 10^{8} \pm 1 \times 10^{8}\left(6.6 \times 10^{8}-8.0 \times 10^{8}\right)$

LAER

$7.1 \times 10^{8} \pm 3 \times 10^{8}\left(5.3 \times 10^{8}-8.9 \times 10^{8}\right)$
Mode of particles $(\mathrm{nm})$

$79.8 \pm 19.8(48.2-102.9)$

Women with elevated aldosterone and low renin (EALR); Women with low aldosterone and elevated renin (LAER); U-Mann Whitney T-test was used to identify differences between groups. * $p<0.05$. Data are presented as mean \pm S.D (range).

\section{Determination of AT1R and LCN2 proteins in plasma sEVs from pregnant women}

A qualitative and semi-quantitative analysis by western blot for AT1R and LCN2 protein was performed in plasma EV lysates from EALR and LAER pregnant women compared with control. AT1R and LCN2 protein from EVs of EALR women showed no significant differences compared to controls (Fig. 2D). Although LCN2 protein abundance had a trend to be higher in EALR group compared to controls $(p=0.057)$ (Fig. 2D). In addition, protein abundance of AT1R and LCN2 in sEVs were similar between LAER and control pregnant women (Fig. 2E).

\section{Discussion}

In the present study, we evaluated the levels of aldosterone and renin in a cohort of 54 normotensive pregnant women. We also described for first time, the presence of AT1R and LCN2 proteins in small extracellular vesicles isolated from maternal circulation, which have been considered as potential biomarker of RAAS and MR activity, respectively.

Currently, there is not a normal range that identifies a lower and upper threshold for normal circulating concentration of aldosterone and renin levels during pregnancy, which is helpful to determine when these physiological changes can become in pathophysiological changes. This has led us to propose in a normotensive group of pregnant women the use of interquartile range $\left(25^{\text {th }}\right.$ percentile $-75^{\text {th }}$ percentile) to identify a normal range for renin and aldosterone. Our results confirmed that aldosterone and renin levels are higher in pregnancy in comparison to the levels reported in non-pregnant women $[3,4]$. Although a group of them show either elevated levels of aldosterone or renin (EALR and LAER group), none of these pregnant women showed clinical symptomatology of high blood pressure during pregnancy. 
In the EALR group (Figure 1A), we suggest these women have an increased renin-independent aldosteronism, which is a condition similar to that seen in primary aldosteronism [28, 35-37], where aldosterone secretion is independent of renin and could be attributed generally to the presence of an autonomous secretion of aldosterone, may due to an adrenal hyperplasia, aldosterone producing cell clusters or aldosterone-producing adenoma [38-40]. In this regard, previous studies in normotensive population have shown the existence of a continuum of renin-independent aldosteronism [30] and a higher risk of developing arterial hypertension in normotensive subjects with elevated ARR [29]. Considering both evidences, we suggest that normotensive pregnant women with EALR have an increased likelihood for future developing of hypertension or CV diseases, may supported by the presence of a second factor or hit (e.g. ischemia/reperfusion, excessive high salt intake, electrolytic imbalance, exogenous/endogenous metabolite, placental sEVs, miRNAs, etc.). Hence, longitudinal studies in these pregnant women are strongly encouraged.

In respect to the women from the LAER group (Figure 1B), we suggest the hyperreninemic phenotype by increase of circulating renin mainly derived from placenta and maternal decidua could favor the synthesis and activity of angiotensin II [41, 42]. In this regard, Lumbers et al postulated the oversecretion of placental renin and placental exosomes enriched with renin and other functional components of the renin-angiotensin system (e.g., renin, angiotensin II, AT1R, AT1R-AA, miRNAs) can directly affect the maternal vascular physiology and further the blood pressure [42].

Recent evidence about the role of sEVs (exosomes) in the pathophysiology of pregnancy, highlight the impact of sEVs and their cargo in the metabolism and function over receptor cells and tissues. Studies between the cargo of $\mathrm{sEV}$ s and MR activation have been carried out in human and animal models [43, 44]. However, studies about the SEVs concentration and cargo in normotensives pregnancies with alterations of aldosterone-renin metabolism have not been performed to date. In this study, we detect for first time the presence of AT1R and LCN2 proteins in plasma sEVs from normotensive pregnant women. $s E V s$ from EALR and LAER pregnant women we did not find changes in protein abundance of EV-AT1R or EV-LCN2, however, a trend to increased levels of EV-LCN2 was determined in EALR group. This finding albeit was not significant should be further explore in a larger cohort of pregnant women, since increasing EV-LCN2 expression has been previously associated to MR activation by aldosterone $[18,19]$. Moreover, a significant increase of $s E V$ mode was found in LAER group compared to controls, suggesting that in LAER the nanovesicles found in plasma are bigger and may have a different biogenesis [45](Table 2).

In summary, we found normotensive pregnant women having either a high circulating aldosterone (9\%) or a high plasma renin (9\%) level. Despite the normal blood pressure, either condition suggest a subclinical status similar to primary aldosteronism or to an hyperreninemia, respectively. Both are subclinical conditions that would evolve to pathological conditions, affecting the maternal vascular and renal physiology, and lately the blood pressure $[42,46]$. In this respect, the presence of AT1R and LCN2 proteins in plasma sEVs isolated from pregnant women are encouraged to be further explored as potential biomarkers of subclinical conditions associated to an unregulated RAAS. 


\section{Declarations}

\section{Funding support}

This study was supported by the following grants: ANID/CONICYT-FONDECYT 1160695, 1190250, 1212006; FONDECYT POSTDOCTORAL 3200646; CONICYT-FONDEQUIP EQM150023; ANID - Millennium Science Initiative Program- IMII P09/016-F, ICN09_016; CORFO BMRC-13CTI-21526-P1; SOCHED 2019-09 and CETREN-UC.

\section{Authors' contributions}

V. P., A. L. CA. C, A.T-C. designed the study, collected, analyzed and interpreted the patient data, analyzed the metabolomics data, wrote the first draft of the manuscript, contributed to discussion, and reviewed the manuscript. V. P., A. L. CA. C, A.T-C. collected and analyzed data, contributed to the statistics of the data, contributed to discussion and reviewed the manuscript. V. P., A. L. CA. C, A.T-C, CE. F. contributed to discussion and reviewed the manuscript. V. P., A. L. enrolled patients, contributed to discussion, and reviewed the manuscript. All authors approved the final version.

\section{References}

1. E.R. Lumbers, K.G. Pringle, Roles of the circulating renin-angiotensin-aldosterone system in human pregnancy. Am. J. Physiol. Regul. Integr. Comp. Physiol. 306(2), R91-R101 (2014). doi:10.1152/ajpregu.00034.2013. PubMed PMID: 24089380. Epub 2013/10/04.

2. C. Gennari-Moser, G. Escher, S. Kramer, B. Dick, N. Eisele, M. Baumann et al., Normotensive blood pressure in pregnancy: the role of salt and aldosterone. Hypertension 63(2), 362-368 (2014). doi:10.1161/HYPERTENSIONAHA.113.02320. PubMed PMID: 24296282. Epub 2013/12/04.

3. E. Landau, L. Amar. Primary aldosteronism and pregnancy. Ann Endocrinol (Paris). 2016;77(2):148160. Epub 2016/05/10. doi:10.1016/j.ando.2016.04.009. PubMed PMID: 27156905

4. P. Soma-Pillay, C. Nelson-Piercy, H. Tolppanen, A. Mebazaa. Physiological changes in pregnancy. Cardiovasc J Afr. 2016;27(2):89-94. doi: 10.5830/CVJA-2016-021. PubMed PMID: 27213856

5. A.H. Affinati, R.J. Auchus, Endocrine causes of hypertension in pregnancy. Gland Surg 9(1), 69-79 (2020). doi:10.21037/gs.2019.12.04. PubMed PMID: 32206600; PubMed Central PMCID: PMCPMC7082268. Epub 2020/03/25.

6. M.A. Sparks, S.D. Crowley, S.B. Gurley, M. Mirotsou, T.M. Coffman. Classical Renin-Angiotensin System in Kidney Physiology. Comprehensive Physiology2011. p. 1201-28

7. A. Nguyen Dinh Cat, A.C. Montezano, D. Burger, R.M. Touyz, I.I. Angiotensin, NADPH Oxidase, and Redox Signaling in the Vasculature. Antioxid. Redox Signal. 19(10), 1110-1120 (2013). doi:10.1089/ars.2012.4641. PubMed PMID: 22530599 
8. C. Savoia, D. Burger, N. Nishigaki, A. Montezano, R.M. Touyz, Angiotensin II and the vascular phenotype in hypertension. Expert Rev. Mol. Med. 13, e11 (2011). Epub 2011/04/01. doi: 10.1017/S1462399411001815. PubMed PMID: 21450123

9. L. Thapa, C.M. He, H.P. Chen, Study on the expression of angiotensin II (ANG II) receptor subtype 1 (AT1R) in the placenta of pregnancy-induced hypertension. Placenta 25(7), 637-641 (2004). doi:10.1016/j.placenta.2004.01.026. PubMed PMID: 15193870. Epub 2004/06/15.

10. P.J. Williams, H.D. Mistry, B.A. Innes, J.N. Bulmer, F. Broughton Pipkin, Expression of AT1R, AT2R and AT4R and their roles in extravillous trophoblast invasion in the human. Placenta 31(5), 448-455 (2010) doi: 10.1016/j.placenta.2010.02.014. PubMed PMID: 20304486

11. F.M. Rogerson, Y. Yao, B.J. Smith, P.J. Fuller, Differences in the determinants of eplerenone, spironolactone and aldosterone binding to the mineralocorticoid receptor*. Clin. Exp. Pharmacol. Physiol. 31(10), 704-709 (2004). doi:https://doi.org/10.1111/j.1440-1681.2004.04079.x

12. J.M.C. Connell, E. Davies, The new biology of aldosterone. J. Endocrinol. 186(1), 1 (2005). doi:10.1677/joe.1.06017

13. S. Alvarez, C. Suazo, A. Boltansky, M. Ursu, D. Carvajal, G. Innocenti et al. Urinary Exosomes as a Source of Kidney Dysfunction Biomarker in Renal Transplantation. Transplantation Proceedings. 2013;45(10):3719-23. doi: https://doi.org/10.1016/j.transproceed.2013.08.079

14. P.J. Fuller, Y.Z. Yao, R. Jin, S. He, B. Martin-Fernandez, M.J. Young et al., Molecular evolution of the switch for progesterone and spironolactone from mineralocorticoid receptor agonist to antagonist. Proc Natl Acad Sci U S A 116(37), 18578-18583 (2019). doi:10.1073/pnas.1903172116. PubMed PMID: 31439819; PubMed Central PMCID: PMCPMC6744879. Epub 2019/08/24.

15. M.E. Baker, Y. Katsu. Progesterone: An enigmatic ligand for the mineralocorticoid receptor. Biochem Pharmacol. 2020;177:113976. Epub 2020/04/20. doi: 10.1016/j.bcp.2020.113976. PubMed PMID: 32305433

16. A. Vecchiola, C.F. Lagos, C.A. Fuentes, F. Allende, C. Campino, C. Valdivia et al., Different effects of progesterone and estradiol on chimeric and wild type aldosterone synthase in vitro. Reprod Biol Endocrinol 11, 76 (2013). doi:10.1186/1477-7827-11-76. PubMed PMID: 23938178; PubMed Central PMCID: PMCPMC3848474. Epub 2013/08/14.

17. C. Campino, P. Trejo, C.A. Carvajal, A. Vecchiola, C. Valdivia, C.A. Fuentes et al., Pregnancy normalized familial hyperaldosteronism type I: a novel role for progesterone? J Hum Hypertens 29(2), 138-139 (2015). doi:10.1038/jhh.2014.49. PubMed PMID: 24943290. Epub 2014/06/20.

18. C. Latouche, S. El Moghrabi, S. Messaoudi, A. Nguyen Dinh Cat, I. Hernandez-Diaz, D. Alvarez de la Rosa et al., Neutrophil gelatinase-associated lipocalin is a novel mineralocorticoid target in the cardiovascular system. Hypertension 59(5), 966-972 (2012). doi:10.1161/HYPERTENSIONAHA.111.187872. PubMed PMID: 22469622. Epub 2012/04/04.

19. A. Tarjus, E. Martinez-Martinez, C. Amador, C. Latouche, S. El Moghrabi, T. Berger et al., Neutrophil Gelatinase-Associated Lipocalin, a Novel Mineralocorticoid Biotarget, Mediates Vascular Profibrotic 
Effects of Mineralocorticoids. Hypertension 66(1), 158-166 (2015).

doi:10.1161/HYPERTENSIONAHA.115.05431. PubMed PMID: 25987661. Epub 2015/05/20.

20. C. Thery, K.W. Witwer, Minimal information for studies of extracellular vesicles 2018 (MISEV2018): a position statement of the International Society for Extracellular Vesicles and update of the MISEV2014 guidelines. J Extracell Vesicles 7(1), 1535750 (2018) doi:

10.1080/20013078.2018.1535750. PubMed PMID: 30637094; PubMed Central PMCID: PMCPMC6322352

21. C. Salomon, G.E. Rice, Chapter Six - Role of Exosomes in Placental Homeostasis and Pregnancy Disorders, in Progress in Molecular Biology and Translational Science, 145, ed. by W.R. Huckle (Academic Press, 2017), pp. 163-179

22. M.D. Mitchell, H.N. Peiris, M. Kobayashi, Y.Q. Koh, G. Duncombe, S.E. Illanes et al., Placental exosomes in normal and complicated pregnancy. Am. J. Obstet. Gynecol. 213(4), S.upplement):S173-S181 (2015). doi:https://doi.org/10.1016/j.ajog.2015.07.001

23. C. Salomon, M.J. Torres, M. Kobayashi, K. Scholz-Romero, L. Sobrevia, A. Dobierzewska et al., A Gestational Profile of Placental Exosomes in Maternal Plasma and Their Effects on Endothelial Cell Migration. PLOS ONE 9(6), e98667 (2014). doi:10.1371/journal.pone.0098667

24. X.-B.L. Hong-Chao Zhang, X.-Y. Shu Huang, H.-X. Bi, L.-X. Wang, Y.-Q. Xie, X.-F. Wang, J. Cao, F.-J. Lv, Xiao, Yang Yang, and Zi-Kuan Guo. Microvesicles Derived from Human Umbilical Cord Mesenchymal Stem Cells Stimulated by Hypoxia Promote Angiogenesis Both In Vitro and In Vivo. Stem Cells and Development 21(18), 3289-3297 (2012). doi:10.1089/scd.2012.0095. PubMed PMID: 22839741

25. E.R.P.P. Carrillo, Lipocalina asociada con la gelatinasa de neutrófilos. Un biomarcador que llegó para quedarse. Medicina Crítica 4, 258-263 (2014)

26. M. Laskowska, B. Leszczyńska-Gorzelak, J. Oleszczuk, Placental angiotensin II receptor AT1R in normotensive patients and its correlation between infant birth weight. European Journal of Obstetrics \& Gynecology and Reproductive Biology 109(2), 166-170 (2003). doi:https://doi.org/10.1016/S0301-2115(03)00079-4

27. P.J. Williams, H.D. Mistry, B.A. Innes, J.N. Bulmer, F. Broughton Pipkin, Expression of AT1R, AT2R and AT4R and Their Roles in Extravillous Trophoblast Invasion in the Human. Placenta 31(5), 448-455 (2010). doi:https://doi.org/10.1016/j.placenta.2010.02.014

28. P.K. Whelton, R.M. Carey, W.S. Aronow, D.E. Casey, K.J. Collins, C.D. Himmelfarb et al. 2017 ACC/AHA/AAPA/ABC/ACPM/AGS/APhA/ASH/ASPC/NMA/PCNA Guideline for the Prevention, Detection, Evaluation, and Management of High Blood Pressure in Adults: A Report of the American College of Cardiology/American Heart Association Task Force on Clinical Practice Guidelines. Hypertension. 2018;71(6):e13-e115. doi: doi:10.1161/HYP.0000000000000065

29. A. Markou, T. Pappa, G. Kaltsas, A. Gouli, K. Mitsakis, P. Tsounas et al., Evidence of Primary Aldosteronism in a Predominantly Female Cohort of Normotensive Individuals: A Very High Odds Ratio for Progression into Arterial Hypertension. The Journal of Clinical Endocrinology \& Metabolism 98(4), 1409-1416 (2013). doi:10.1210/jc.2012-3353 
30. R. Baudrand, F.J. Guarda, C. Fardella, G. Hundemer, J. Brown, G. Williams et al., Continuum of ReninIndependent Aldosteronism in Normotension. Hypertension 69(5), 950-956 (2017). doi:10.1161/HYPERTENSIONAHA.116.08952. doi

31. A. Tapia-Castillo, R. Baudrand, A. Vaidya, C. Campino, F. Allende, C. Valdivia et al., Clinical, Biochemical, and Genetic Characteristics of "Nonclassic" Apparent Mineralocorticoid Excess Syndrome. J Clin Endocrinol Metab 104(2), 595-603 (2019). doi:10.1210/jc.2018-01197. PubMed PMID: 30239803. Epub 2018/09/22.

32. S. Sarker, K. Scholz-Romero, A. Perez, S.E. Illanes, M.D. Mitchell, G.E. Rice et al., Placenta-derived exosomes continuously increase in maternal circulation over the first trimester of pregnancy. J Transl Med 12, 204 (2014). doi:10.1186/1479-5876-12-204. PubMed PMID: 25104112; PubMed Central PMCID: PMCPMC4283151. Epub 2014/08/12.

33. A. Tapia-Castillo, D. Guanzon, C. Palma, A. Lai, E. Barros, F. Allende et al., Downregulation of exosomal miR-192-5p and miR-204-5p in subjects with nonclassic apparent mineralocorticoid excess. J Transl Med 17(1), 392 (2019). doi:10.1186/s12967-019-02143-8. PubMed PMID: 31775784; PubMed Central PMCID: PMCPMC6880399. Epub 2019/11/30.

34. B. Fuenzalida, C. Cantin, S. Kallol, L. Carvajal, V. Pasten, S. Contreras-Duarte et al., Cholesterol uptake and efflux are impaired in human trophoblast cells from pregnancies with maternal supraphysiological hypercholesterolemia. Sci Rep 10(1), 5264 (2020). doi:10.1038/s41598-02061629-4. PubMed PMID: 32210256; PubMed Central PMCID: PMCPMC7093446. Epub 2020/03/27.

35. P. Mulatero, M. Stowasser, K.C. Loh, C.E. Fardella, R.D. Gordon, L. Mosso et al., Increased diagnosis of primary aldosteronism, including surgically correctable forms, in centers from five continents. J Clin Endocrinol Metab 89(3), 1045-1050 (2004). doi:10.1210/jc.2003-031337. PubMed PMID: 15001583. Epub 2004/03/06.

36. Y. Takeda, S. Karashima, T. Yoneda, Primary aldosteronism, diagnosis and treatment in Japan. Rev Endocr Metab Disord 12(1), 21-25 (2011). doi:10.1007/s11154-011-9164-6. PubMed PMID: 21424323. Epub 2011/03/23.

37. L. Mosso, C. Carvajal, A. Gonzalez, A. Barraza, F. Avila, J. Montero et al., Primary aldosteronism and hypertensive disease. Hypertension 42(2), 161-165 (2003).

doi:10.1161/01.HYP.0000079505.25750.11. PubMed PMID: 12796282

38. K. Omata, S.A. Tomlins, W.E. Rainey, Aldosterone-Producing Cell Clusters in Normal and Pathological States. Horm Metab Res 49(12), 951-956 (2017). doi:10.1055/s-0043-122394. PubMed PMID: 29202494; PubMed Central PMCID: PMCPMC5770278. Epub 2017/12/05.

39. A. Martinez-Aguayo, M. Aglony, C. Campino, H. Garcia, R. Bancalari, L. Bolte et al., Aldosterone, plasma Renin activity, and aldosterone/renin ratio in a normotensive healthy pediatric population. Hypertension 56(3), 391-396 (2010). doi:10.1161/HYPERTENSIONAHA.110.155135. PubMed PMID: 20696993. Epub 2010/08/11.

40. C.E. Fardella, L.M. Mosso, C.A. Carvajal, [Primary aldosteronism]. Rev. Med. Chil. 136(7), 905-914 (2008). Epub 2008/10/25. doi: /S0034-98872008000700014. PubMed PMID: 18949169 
41. W.A. Hsueh, J.A. Luetscher, E.J. Carlson, G. Grislis, E. Fraze, A. McHargue, Changes in active and inactive renin throughout pregnancy. J Clin Endocrinol Metab 54(5), 1010-1016 (1982). doi:10.1210/jcem-54-5-1010. PubMed PMID: 7037818. Epub 1982/05/01.

42. E.R. Lumbers, S.J. Delforce, A.L. Arthurs, K.G. Pringle, Causes and Consequences of the Dysregulated Maternal Renin-Angiotensin System in Preeclampsia. Front Endocrinol (Lausanne) 10, 563 (2019). doi:10.3389/fendo.2019.00563. PubMed PMID: 31551925; PubMed Central PMCID:

PMCPMC6746881. Epub 2019/09/26.

43. L. Lyu, H. Wang, B. Li, Q. Qin, L. Qi, M. Nagarkatti et al., A critical role of cardiac fibroblast-derived exosomes in activating renin angiotensin system in cardiomyocytes. J. Mol. Cell. Cardiol. 89, 268279 (2015). doi:https://doi.org/10.1016/j.yjmcc.2015.10.022

44. G. Pironti, R.T. Strachan, D. Abraham, S.M.W. Yu, M. Chen, W. Chen et al., Circulating Exosomes Induced by Cardiac Pressure Overload Contain Functional Angiotensin II Type 1 Receptors. Circulation 131(24), 2120-2130 (2015). doi:10.1161/CIRCULATIONAHA.115.015687. doi

45. E. Willms, H.J. Johansson, I. Mager, Y. Lee, K.E. Blomberg, M. Sadik et al., Cells release subpopulations of exosomes with distinct molecular and biological properties. Sci Rep 6, 22519 (2016). doi:10.1038/srep22519. PubMed PMID: 26931825; PubMed Central PMCID: PMC4773763 46. C.A. Carvajal, A. Tapia-Castillo, A. Vecchiola, R. Baudrand, C.E. Fardella. Classic and Nonclassic Apparent Mineralocorticoid Excess Syndrome. J Clin Endocrinol Metab. 2020;105(4). Epub 2020/01/08. doi: 10.1210/clinem/dgz315. PubMed PMID: 31909799

\section{Figures}
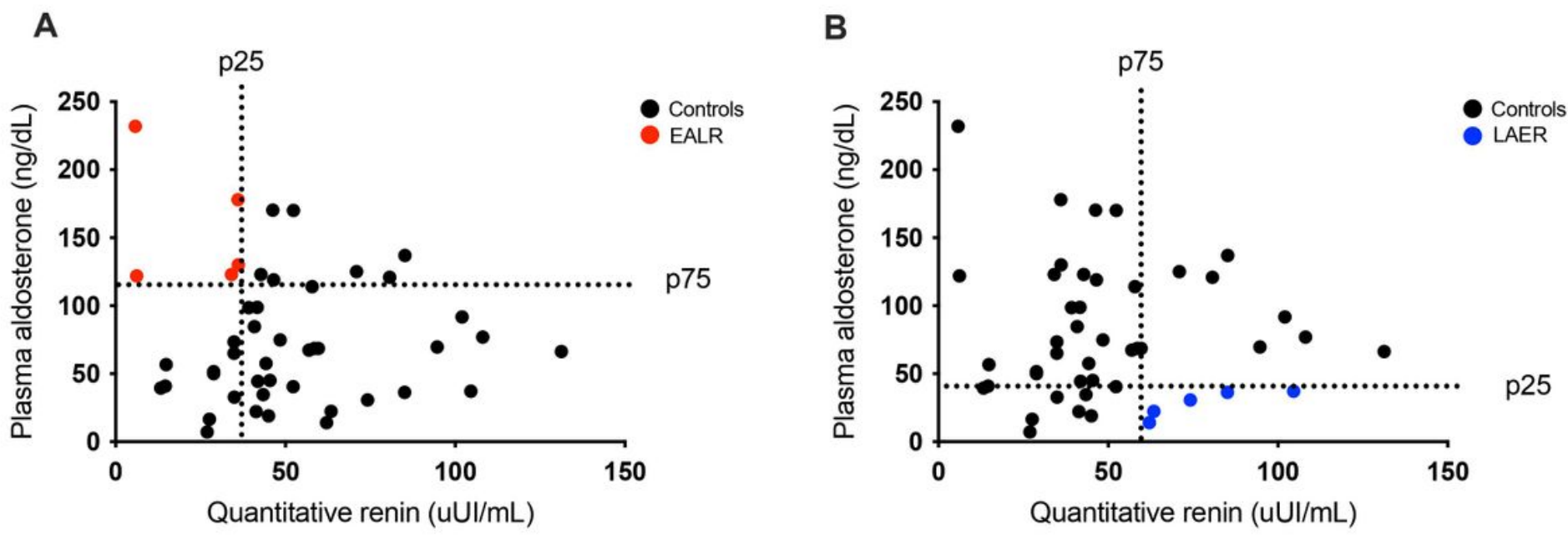

\section{Figure 1}

Identification of groups of pregnant women with elevated levels of aldosterone or renin. (A) Women with elevated aldosterone and low renin (EALR, aldosterone $>75$ th percentile, renin <25th percentile; $n=5)$ are shown in red dots. (B) Women with low aldosterone and elevated renin (LAER, aldosterone $<25$ th 
percentile; renin $>75$ th percentile, $n=5$ ) are shown in blue dots. Other normotensive pregnant women $(n=44)$ were considered as controls.

A

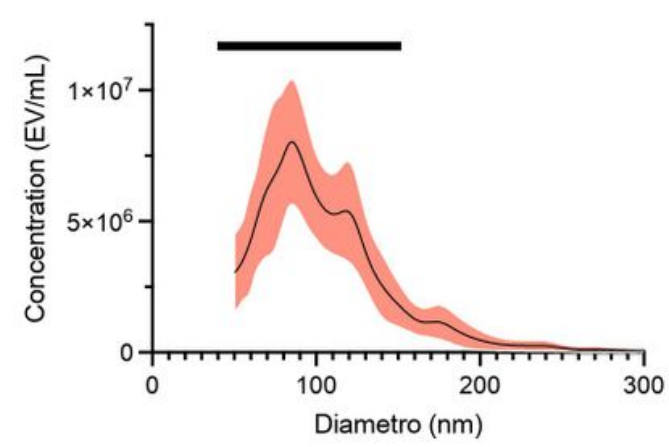

D
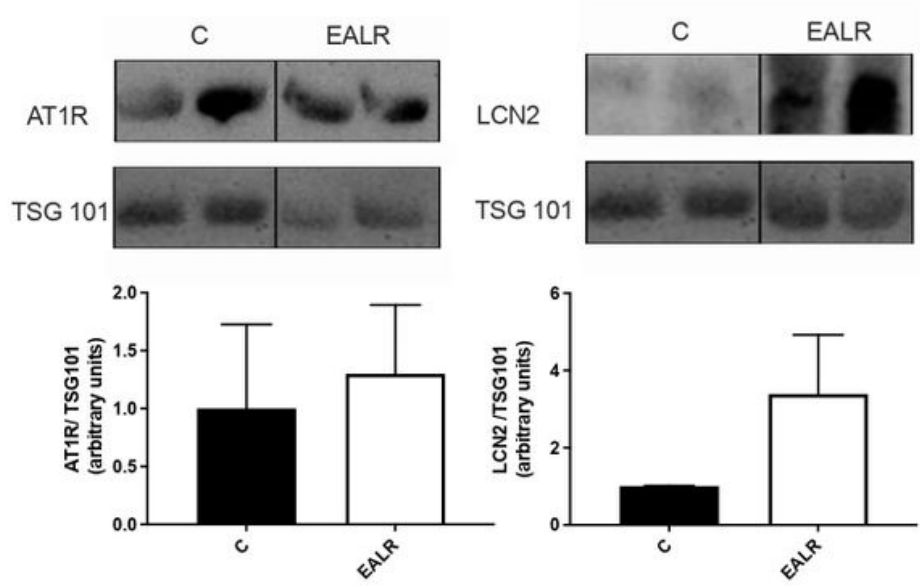

B

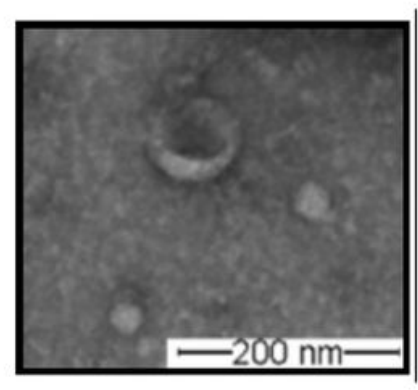

C

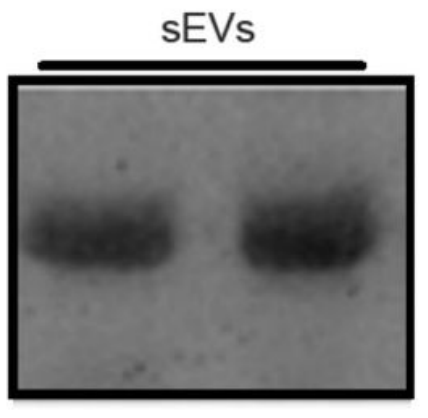

$\mathrm{E}$

TSG 101
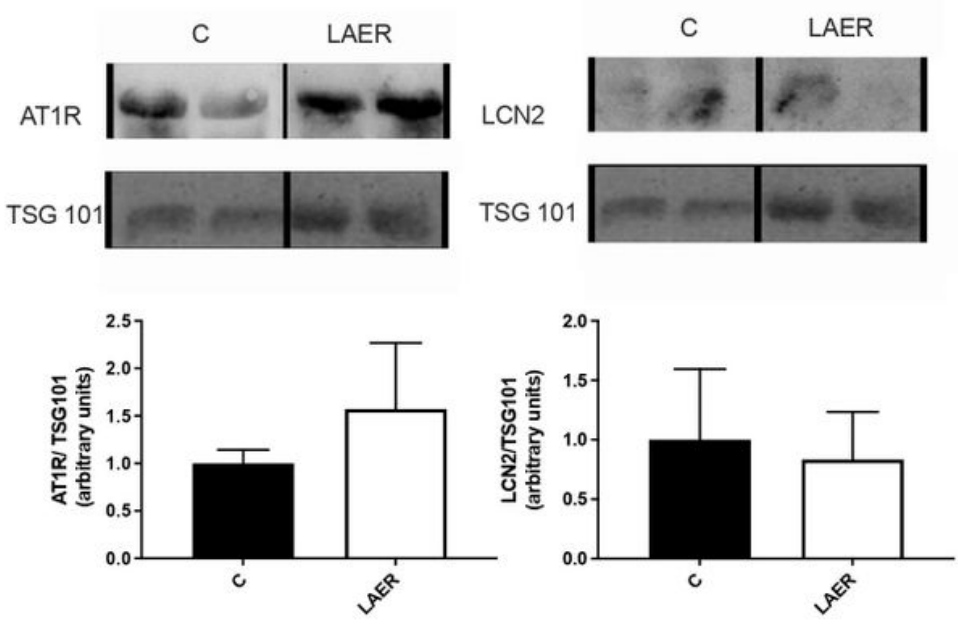

\section{Figure 2}

Characterization of plasma sEVs isolated from normotensive pregnant women. (A) Plot showing the mean particle size (including standard error) vs concentration of sEV from NTA data. (B) Representative image of $s E V s$ morphology determined by electron microscopy in normotensives pregnancies. (C) Representative western blot for TSG101 in sEVs isolated from normotensives pregnancies ( $n=18)$. (D) Representative western blots for AT1R and Lipocalin-2 (LCN2) in plasma sEVs isolated from normotensives pregnancies with EALR. (E) Representative western blots for AT1R and Lipocalin-2 (LCN2) in plasma sEVs isolated from normotensives pregnancies with LAER. Protein levels were normalized for TSG101. U-Mann Whitney T-test was used to identify differences between groups. The bars plot shows the mean value \pm S.E.M. 